\title{
Study on the Influence of Soil Moisture Content on the Probability of Landslide Instability
}

\author{
DENG Si-jia ${ }^{1, a}$, CHEN Ya-die $^{1, b}$, HOU Jing-feng ${ }^{1, c}$, FENG Jian-hua ${ }^{1, d}$, YANG \\ Ya-lan ${ }^{1, e}$, WU Xin ${ }^{1, f}$ \\ ${ }^{1}$ Engineering School, Sichuan Normal University, Chengdu 610101,China \\ a354961086@qq.com, b353998421@qq.com, '332794095@qq.com, d1213342593@qq.com, \\ '946122858@qq.com, ${ }^{\mathrm{f}} 95216533 @ q q . c o m$
}

Keywords: landslide; Monte-Carlo method; moisture content; direct shear test; probability of instability

Abstract. Rainfall reduces the possibility of increasing landslide instability. In order to study the stability of landslides with multi-stage sliding surface under rainfall conditions, this paper studies the physical and mechanical properties of soils with different moisture contents through direct shear tests of unsaturated soils And then analyze the safety factor and the probability of instability under multi-stage landslide. However, the traditional methods for analyzing the stability of landslides are relatively definite and have certain limitations, and the uncertainties of landslides are not fully considered. Therefore, this paper takes Xiaya River landslide in Baoji City, Shaanxi Province as an example, and uses Monte-Carlo simulation method and Bishop method to analyze the safety factor and the probability of instability of the landslide under different moisture contents.

\section{Introduction}

Most landslides in our country are concentrated in some parts of South China, of which the average annual precipitation in most cities are larger than that in China, and many of the landslides are caused by heavy rainfall ${ }^{[1-3]}$. Therefore, it is very important to study the effects of rainfall on landslide stability The impact is of great significance. Hanjian ${ }^{[4]}$ established the physical model of slope test to analyze the relationship between the transient moisture content and rainfall at different depths in the loess slope. Ranjan Kumar Dahal ${ }^{[5]}$ studied the rainfall threshold of landslide; Wei Lai ${ }^{[6]}$ using SPSS software to get the regression model of rainfall factors, and then simulate the landslide status under different conditions; Liu Hualei ${ }^{[7]}$ et al analyzed the evolution of landslide cracks under rainfall and its impact on stability; Chen Lixia ${ }^{[8]}$ and so on People have studied the application of rainfall extreme value and its recurrence yield in probability analysis of rainfall landslide. The above studies on landslide stability under rainfall conditions are of great value.

In this paper, using unsaturated soil direct shear test to obtain the moisture content of soil physical and mechanical parameters of the reduction factor. Taking Xiaya River landslide as an example, the stability under different conditions was analyzed. The probability of landslide instability was calculated based on Monte-Carlo and then made the evaluation.

\section{Experimental Study on Physical and Mechanical Properties of Loess by Moisture Content}

Because loess has many voids and weak cementation, and has moisture sensitivity and dynamic vulnerability ${ }^{[9]}$, the stability of loess slopes is often affected by natural conditions. Among them, rainfall will change the moisture content of slope soil, and the shear strength indexes of slope soil is directly affected by the moisture content ${ }^{[10]}$. The size of it and the depth affect the mechanical properties of the loess to different degrees ${ }^{[11]}$. Therefore, the moisture content has a great influence on the stability of the loess slope. In this paper, only the influence of moisture content on the reduction of cohesion and internal friction angle of loess is considered. First determined the moisture content of natural loess sample w. 
Using direct shear test of unsaturated soil to determine the cohesion and internal friction angle of the loess under different moisture contents, The curves were fitted to obtain the law of shear strength indexes with the change of moisture contents, and the influence of moisture content on slope stability was obtained.

Determination of loess sample parameters. Take overlying loess of the Chang'an District, Xi'an double bamboo village as sample soil, stratum data show that the soil layers are as follows: (1)Quaternary loess and red paleosol,(2)silty clay,(3)mild clay and sand,(4)schist and granite. According to the different moisture content,configured into 4 groups of samples. The cohesion and internal friction angle of the loess under different moisture contents were determined by the direct shear test of unsaturated soil. The principle is as follows: 4 groups of soil samples with different moisture contents are directly sheared along the fixed shearing surface under different normal pressures to obtain the shear stress corresponding to the sheared soil. That is, the shear strength $\tau \mathrm{f}$, and then according to the strength of the envelope to determine the soil shear strength index $c$ and $\varphi$. Test sample shown in Figure 1.

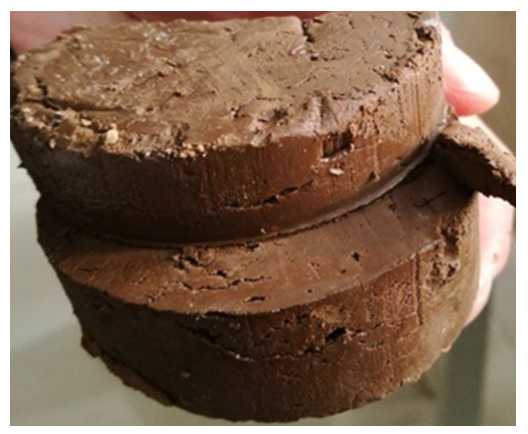

Fig. 1 Test site

When the moisture content is $19 \%$ and $23 \%$ respectively, taking the normal stress as $100 \mathrm{kPa}$ as an example, the shear stress-shear displacement curve of loess is shown in Figure 2. According to Figure 2, we can determine the corresponding shear strength of four soil samples with different moisture contents under the normal stress of $100 \mathrm{kPa}$. Similarly, Similarly, we can get the shear strength under other conditions, as shown in Table 1.
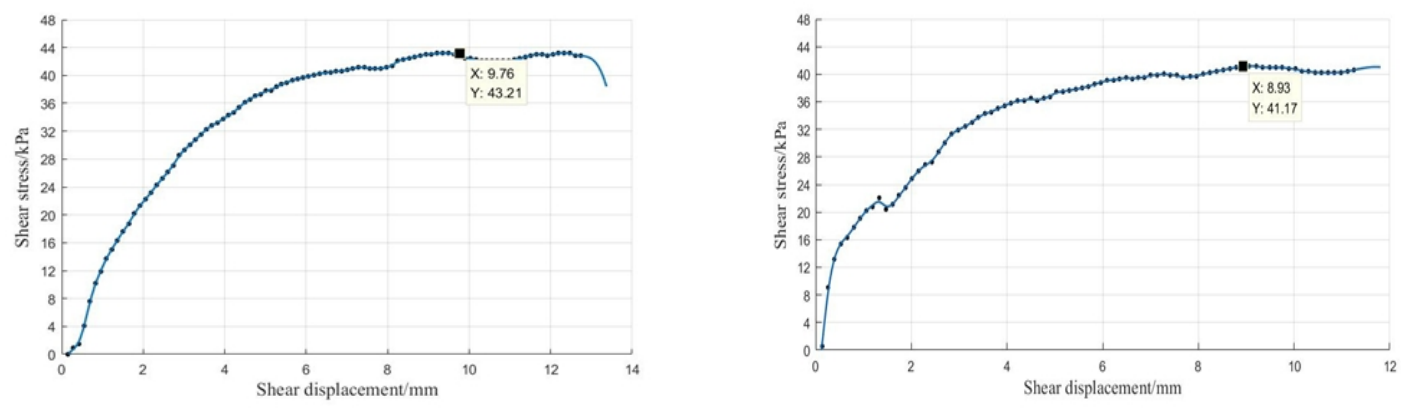

Fig.2 Relationship between shearing stress and shearing displacement when the normal stress is $100 \mathrm{kPa}$, the moisture content is $19 \%$ (left), $23 \%$ (right)

Table 1 Tests obtained under different conditions of shear strength

\begin{tabular}{cccc}
\hline & \multicolumn{3}{c}{ normal stress $\sigma[\mathrm{kPa}]$} \\
moisture content $\mathrm{w}[\%]$ & 25 & 50 & 100 \\
\hline 19 & $21.88[\mathrm{kPa}]$ & $33.20[\mathrm{kPa}]$ & $43.21[\mathrm{kPa}]$ \\
23 & $19.29[\mathrm{kPa}]$ & $28.37[\mathrm{kPa}]$ & $41.17[\mathrm{kPa}]$ \\
26 & $18.33[\mathrm{kPa}]$ & $23.92[\mathrm{kPa}]$ & $36.67[\mathrm{kPa}]$ \\
30 & $15.76[\mathrm{kPa}]$ & $18.55[\mathrm{kPa}]$ & $28.37[\mathrm{kPa}]$ \\
\hline
\end{tabular}

According to the shear strength under different conditions, the strength envelope (shown in Figure 3) can be used to determine the corresponding shear strength indexes $\mathrm{c}$ and $\varphi$ for loess at different moisture contents, as shown in Table 2. 

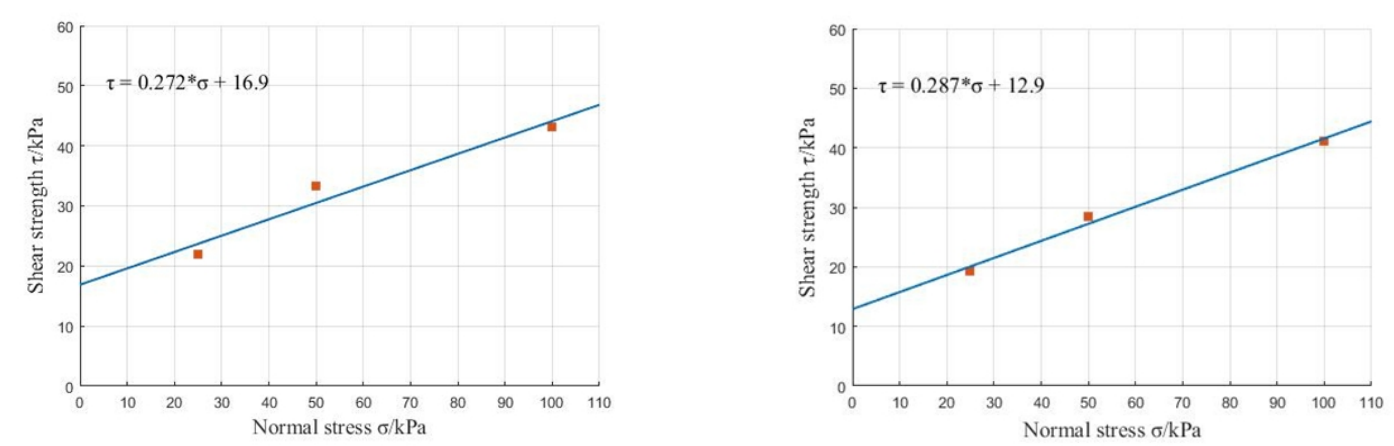

Fig.3 Envelope of soil samples with moisture content of $19 \%$ (left), 23\% (right)

Table 2 Corresponding cohesion and internal friction angle at different moisture contents

\begin{tabular}{ccccc}
\hline moisture content $\mathrm{w}[\%]$ & 19 & 23 & 26 & 30 \\
\hline cohesion $[\mathrm{kPa}]$ & 16.900 & 12.900 & 12.000 & 10.800 \\
internal friction angle $\left[{ }^{\circ}\right]$ & 15.615 & 16.429 & 14.102 & 9.871 \\
\hline
\end{tabular}

loess parameters to determine the reduction factor. Through four groups of soil samples with different moisture contents of direct shear test of unsaturated soil, the cohesion and internal friction angle of the loess under different conditions were obtained. Using different moisture contents as the abscissa and the cohesion c or internal friction angle $\varphi$ as the ordinate, using MATLAB R2016a to fit the curve shown in Figure 4. Through the analysis of Fig. 4, the reduction factor of cohesion and internal friction angle are respectively 0.5314 and 0.5397 .
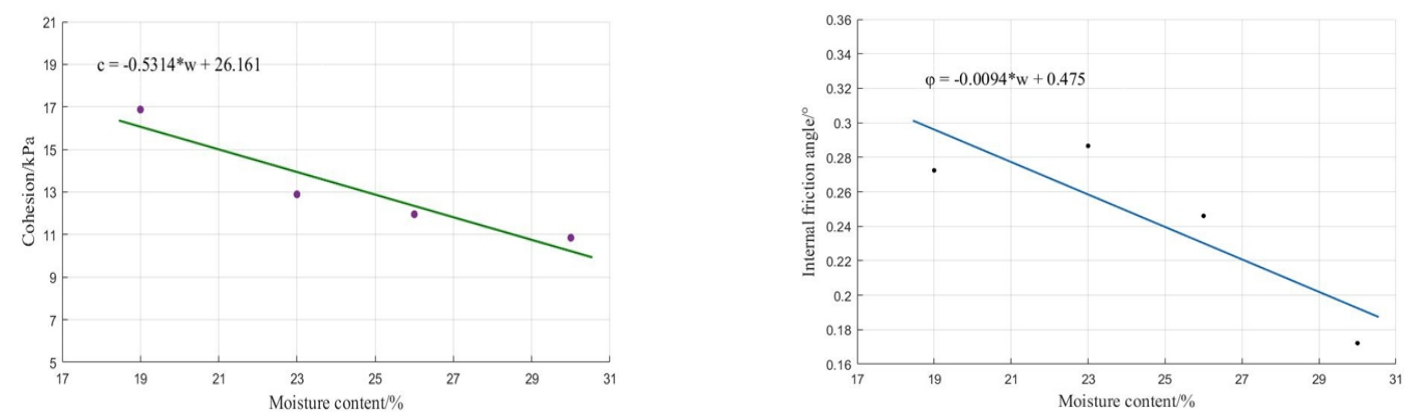

Fig.4 Trends of cohesion (left) and internal friction (right) at different moisture contents

\section{project case}

Project Overview. Xiaya River landslide is located in Baoji City, Shaanxi Province, developed in Qingjiang River tributary of the slope The slope body presents a saddle shape on the plane with a width of about $210 \mathrm{~m}$ and a length of about $290 \mathrm{~m}$. The relative height of the landslide is about $90 \mathrm{~m}$, the average slope is $20^{\circ}$, and the main sliding direction is about $322^{\circ}{ }^{[12]}$. There are 4 layers of soil layers in this landslide, and the components from top to bottom are as follows:(1)Quaternary Pleistocene loess paleosol,(2)Tertiary hard clay,(3)Tertiary sandy gravel,(4)granite ${ }^{[12]}$. There are four sliding surfaces in the landslide. Because of the rainfall, the moisture content of the upper soil generally changes. Therefore, the first and second sliding surfaces are analyzed in this paper, and the two-stage sliding surfaces are in the Pleistocene loess ${ }^{[12]}$. Therefore, this paper analyzed the stability of the two-level sliding surface of Xiaya River at different moisture contents, considered the effect of it on the cohesion $\mathrm{c}$ and internal friction angle $\varphi$ of the landslide, and calculated the safety factor of the loess slope and landslide probability.

Xiaya River landslide mechanical parameters. Through the measurement, the moisture content of the loess in natural state is $6.09 \%$, the initial value of the mean value of cohesion and internal friction angle is shown in Table 3, and the initial values of standard deviation of cohesion and internal 
friction angle are shown in Table 4. Moisture content of Xiaya River landslide was $8 \%$ and $12 \%$ respectively, the first-order slip surface can be calculated from the coalescence coefficient and the reduction coefficient of internal friction angle calculated above The average shear strength indexes of $8 \%$ moisture content : $\mathrm{c}_{8}=28.59 \mathrm{kPa}$ and $\varphi_{8}=15.27^{\circ}$, the average shear strength indexes of $12 \%$ moisture content : $\mathrm{c}_{12}=26.46 \mathrm{kPa}, \varphi_{12}=13.11^{\circ}$; Moisture content of $8 \%$ of the average shear strength indexes of secondary slip surface: $\mathrm{C}_{8}^{\prime}=26.68 \mathrm{kPa}$ and $\varphi_{8}^{\prime}=16.48^{\circ}$. The average shear strength at $12 \%$ moisture content: $\mathrm{c}^{\prime}{ }_{12}=24.56 \mathrm{kPa}, \varphi_{12}^{\prime}=14.31^{\circ}$. Finishing as shown in Table 3 .

Table 3 different moisture content shear strength index

\begin{tabular}{cccrcrc}
\hline moisture content & \multicolumn{2}{c}{$6.09[\%]$} & \multicolumn{2}{c}{$8[\%]$} & \multicolumn{2}{c}{$12[\%]$} \\
shear strength index & $\mathrm{c}[\mathrm{kPa}]$ & $\varphi\left[^{\circ}\right]$ & $\mathrm{c}[\mathrm{kPa}]$ & $\varphi\left[^{\circ}\right]$ & $\mathrm{c}[\mathrm{kPa}]$ & $\varphi\left[^{\circ}\right]$ \\
\hline first-order slip surface & 29.6 & 16.3 & 28.59 & 15.27 & 26.46 & 13.11 \\
Secondary slip surface & 27.7 & 17.5 & 26.68 & 16.48 & 24.56 & 14.31 \\
\hline
\end{tabular}

Table 4 Xiaya River two slip surface of the standard deviation of c , $\varphi$

\begin{tabular}{ccc}
\hline shear strength index & cohesion $\mathrm{c}[\mathrm{kPa}]$ & internal friction angle $\varphi\left[{ }^{\circ}\right]$ \\
\hline first-order slip surface & 5.36 & 1.87 \\
Secondary slip surface & 3.25 & 1.37 \\
\hline
\end{tabular}

Xiaya River landslide probability of failure to calculate. From the data in Table 3 and Table 4, a number of c, $\varphi$ are randomly generated by Monte-Carlo method and brought into the Bishop formula. A number of safety factors are obtained. And then calculated the probability of instability of the two slip surfaces of Xiaya River when the Water content is $8 \%$ and $12 \%$. The results are shown in Table 5 . Table 5 Xiaya River landslide probability of instability

\begin{tabular}{lcccc}
\hline & $\begin{array}{c}\text { moisture } \\
\text { content }\end{array}$ & $\begin{array}{c}\text { mean value of } \\
\text { stability }\end{array}$ & $\begin{array}{c}\text { standard } \\
\text { deviation of } \\
\text { stability }\end{array}$ & $\begin{array}{c}\text { probability of } \\
\text { instability }\end{array}$ \\
\hline first-order slip surface & $8 \%$ & 1.054 & 0.119 & $31.1 \%$ \\
Secondary slip surface & $12 \%$ & 0.899 & 0.081 & $86.0 \%$ \\
& $8 \%$ & 0.964 & 0.102 & $61.8 \%$ \\
\hline
\end{tabular}

\section{Conclusions}

1) In this paper, the influence of moisture content on the physico-mechanical properties of loess is analyzed by the direct shear test of unsaturated soil. By using the reduction coefficient to quantify the change of soil parameters, a large number of random numbers are extracted by Monte-Carlo method and then reflect The probability of landslide instability under special conditions is a more realistic and realistic method than the traditional deterministic method.

2) Through the probability of landslide instability under different moisture contents, it is easy to see that when the moisture content is $8 \%$ and $12 \%$, the average safety factor of Xiaya River landslide is less than 1.0, which belongs to unstable landslide ${ }^{[13]}$. And the probability of instability increases greatly, the probability of first-order slip surface instability increases from $31.1 \%$ to $86.0 \%$, and the secondary slip surface probability increases from $61.8 \%$ to $81.3 \%$, both of which are much larger than the probability when the moisture content is $6.09 \%$. Therefore, the influence of moisture content should be considered when calculating the slope safety factor and the probability of instability in areas with sufficient rainfall.

3) From the calculation results, it can be seen that the probability of instability of the secondary slip surface is much larger than that of the primary slip surface when the soil moisture content is $8 \%$. When the moisture content is $12 \%$, the probability of instability is similar. Showing that when the moisture content is $8 \%$, the stability of the secondary sliding surface is more affected. 


\section{Acknowledgements}

1, The project of the State Administration of Work Safety, key technologies for prevention of major accidents in production safety in 2017 ( sichuan-0004-2017AQ )

2, The key project of the education department of Sichuan Province ( 18ZA0407 )

\section{References}

[1] Wang Dingjian, Tang Huiming, Li Changdong, Ge Yunfeng, Yi Xianlong.Stability Analysis of Landslide under Heavy Rain [J]. Rock and Soil Mechanics, 2016, 37 (2): 439-440.

[2] Gao Xiaoming.Analysis on the Sensitivity of Loess Slope Stability under Rainfall Conditions [D] .Shaanxi: Chang'an University, 2016.

[3] He Keqiang, Zhou Dunyun, Wang Sijing.Analysis of Loading-unloading Response Ratio of Rainfall-type Accumulation Landslide and Its Prediction and Its Significance [J] .Chinese Journal of Rock Mechanics and Engineering, 2004, (16): 2665-2670.

[4] Han Jiaming. Research on failure mechanism of loess slope under rainfall infiltration and disaster mitigation technology [D] .Shaanxi: Xi'an University of Science and Technology, 2015.

[5] Ranjan Kumar Dahal,Shuichi Hasegawa. Representative rainfall thresholds for landslides in the Nepal Himalaya[J]. Geomorphology, 2008, 100(3-4): 429-443.

[6] Wei Lai. Rainfall induced landslide prediction model [D]. Chongqing: Chongqing Jiaotong University, 2013.

[7] Liu Hualei, Xu Zemin, Zhang Yong, Wang Zhiqi. Evolution Mechanism of Slope Cracks under Rainfall and Its Impact on Slope Stability - A Case Study of Dingjiacao Landslide in Shuangbai County, Yunnan Province [J] 26 (1): 26-29.

[8] Chen Lixia, Yin Kunlong, Liu Changchun.Research on Rainfall Reappearance Period and Its Probability Analysis for Landslide [J] .Journal of Engineering Geology, 2012,20 (5): 746-750.

[9] Pu Xiaowu. Large-scale Shaking Table Test Study on Loess Slope Instability under the Coupling of Earthquake and Rainfall [D]. Lanzhou Seismological Research Institute, China Earthquake Administration, 2016.

[10] Wang Li, Liang Hong. Effect of moisture content on shear strength of silty clay [J] .Journal of Inner Mongolia Agricultural University, 2009,30 (1): 170-174.

[11] Wen Yubin, Zhang Zhaohong, Zhu Ruoxi.Analysis on the Influence of Moisture Content on Stability of Slope of Piled Excavation [J] .Journal of Highway and Transportation, 2013 (05): 107-110.

[12] He Shujun, Zhang Chunshan, Wu Shuren, Sun Weifeng, Ye Siyuan, Wang Tao, Xin Peng.Analysis of reliability of multi-loess landslides based on Monte-Carlo method [J] .Chinese Journal of Geology, 2008 (11): 1822-1831.

[13] Qiu Hai-Jun, Cui Peng, Hu Sheng, Liu Qi, Wang Yan-Min, Gao Yu, Deng Mei-Feng.Frequency distribution of loess landslides in different landform types in northern Shaanxi Loess Plateau [J] .Earthquake Science and Technology, 2016, 41 (2): 346-349. 